\title{
Persistence of sulfur dioxide emissions in OECD countries between 1750-2014: A fractional integration approach
}

Sakiru Adebola Solarin, Multimedia University, Melaka, Malaysia

Luis A. Gil-Alana, University of Navarra, Pamplona, Spain and Universidad Francisco de Vitoria, Madrid, Spain*

Maria Jesus Gonzalez-Blanch, Universidad Francisco de Vitoria, Madrid, Spain

\begin{abstract}
In this paper the degree of persistence of the sulfur dioxide emissions in a group of 37 OECD countries is examined by looking at the order of integration of the series. However, instead of using integer degrees of differentiation (i.e., 1 in case of unit roots and 0 for stationarity), fractional values are also considered. The results indicate high degrees of persistence and very little evidence of mean reversion. In fact, this property only holds for the three Latin American countries examined, namely Chile, Colombia and Mexico if the error follows a white noise process. If autocorrelation is permitted, however, the confidence intervals are wider and mean reversion is not found in any single case.
\end{abstract}

JEL Classification: C22; Q50; Q53; Q58

Keywords: Sulphur dioxide emissions; persistence; long range dependence

$\begin{array}{ll}* \text { * Corresponding author: } & \text { Prof. Luis Alberiko Gil-Alana } \\ & \text { University of Navarra } \\ & \text { Department of Economics } \\ & \text { E-31009 Pamplona } \\ & \text { Spain }\end{array}$

Email: alana@unav.es

Prof. Luis A. Gil-Alana gratefully acknowledges financial support from the MINEIC-AEI-FEDER ECO2017-85503-R project from 'Ministerio de Economía, Industria y Competitividad' (MINEIC), 'Agencia Estatal de Investigación' (AEI) Spain and 'Fondo Europeo de Desarrollo Regional' (FEDER). He also acknowledges support from an internal Project of the Universidad Francisco de Vitoria.

\section{Comments from the Editor and two anonymous reviewers are gratefully acknowledged.}




\section{Introduction}

Combustion of sulfur-containing fuels including oil and coal, leads to the formation of sulfur dioxide $\left(\mathrm{SO}_{2}\right)$. It is produced from fuel combustion in the air, land and water transportation industries. However, power stations account for more $\mathrm{SO}_{2}$ emissions than the remaining causes of the pollutant. $\mathrm{SO}_{2}$ is one of the pollutants regarded as air contaminants by most developed countries (Srivastava, 2000). When $\mathrm{SO}_{2}$ spreads into the atmosphere it forms fine particulate matter and sulfuric acid, secondary pollutants that have important negative impacts on people's health, the economy and the environment. (McLinden et al, 2016). Similar to other sulfur oxides, $\mathrm{SO}_{2}$ emissions can cause acid rain which results in the damage of the ecosystems. At high concentrations, it can impair plants and trees by harming foliage and diminishing growth (Environmental Protection Agency, 2019).

Based on the importance of $\mathrm{SO}_{2}$ emissions and the negative consequences that $\mathrm{SO}_{2}$ emission buildup poses in the economy, especially on people's health, numerous features of the pollutant emissions have been examined in the extant literature such as the determining factors of $\mathrm{SO}_{2}$ emissions (Managi et al, 2008; Zhou et al., 2017; Yang et al., 2017; Liu et al., 2019). There are also some articles that examine the convergence of $\mathrm{SO}_{2}$ emissions (Solarin and Tiwari, 2020; Zhang et al., 2020). One of the areas that has received limited attention in the existing literature is the persistence of $\mathrm{SO}_{2}$ emissions. The literature on the persistence of pollution indicators has been dominated by issues such as the persistence of $\mathrm{CO}_{2}$ emissions (Belbute and Pereira, 2017). The trend observed for $\mathrm{SO}_{2}$ emissions is quite different from the trend that $\mathrm{CO}_{2}$ emissions has followed over the years (Solarin and Tiwari, 2020). The policies and methods aimed at reducing one or other type of pollutant emission differ considerably.

The important aspects of testing for persistence of $\mathrm{SO}_{2}$ emissions are numerous. First, the lack of stationarity indicates that policy shocks to the $\mathrm{SO}_{2}$ emissions brought 
about by the use of technologies or the imposition of standards or laws aimed at lowering $\mathrm{SO}_{2}$ emissions will be permanent (Sidneva and Zivot, 2014). An example of such technologies is the wet system (which involves the mixing of crushed lime or limestone with water, which is then sprayed into the sulfur containing flue gases). Other examples are dry or semi-dry systems (which involve injecting a slurry of alkali sorbent, usually slaked lime, into the flue gases in a fine spray, following which the heat from the flue gases leads to evaporation of water as well as cooling the gases as it does so). Examples of current legislation and standards include the Clean Air Act of 1970 as well as the Energy Policy Conservation Act of 1975 in the United States; On-Road Vehicle and Engine Emission Regulations introduced through the Canadian Environmental Protection Act of 1999; and the various European Union Emission Standards for Light Commercial Vehicles (Timilsina and Dulal, 2009). Conversely, stationarity of $\mathrm{SO}_{2}$ emissions implies that policy shocks to $\mathrm{SO}_{2}$ emissions will have transient impacts.

An additional benefit is that from an econometrics viewpoint, nonstationarity in $\mathrm{SO}_{2}$ emissions series has important consequences for the environmental Kuznets curve and (EKC) papers have employed $\mathrm{SO}_{2}$ emissions as an indicator of pollutant emissions. A handful of EKC papers have relied on the assumption that there is trend stationarity in the pollutant emissions (Sidneva and Zivot, 2014). However, the EKC studies that use the level version of a nonstationary $\mathrm{SO}_{2}$ emission (as the dependent variable) while the dependent variable such as real gross domestic product is also nonstationary, are likely to generate unreliable results (Newbold and Granger, 1974). In other words, econometric methods including the ordinary least squares (OLS) approach that are based on the premise that all the series in the analysis are stationary can yield spurious results, if the series are actually nonstationary (Hendry and Juselius, 2000). 
Moreover, there is limited possibility of convergence among a set of series if the series are not individually stationary at level (Nieswiadomy and Strazicich., 2004). Therefore, any suggestion of convergence on the relative $\mathrm{SO}_{2}$ emissions might not be valid if the $\mathrm{SO}_{2}$ emissions series are not stationary at level.

The aim of the present paper is to extend the existing literature on pollutant emissions by examining the persistence of sulfur emissions in 37 OECD countries during the period 1750-2014. In order to do that, we adopt long range dependence techniques based on fractional integration, which is a more flexible method than the common approaches based on integer differentiation, using ARMA-ARIMA models corresponding to orders of integration of 0 and 1 respectively. This is relevant because we allow for a higher degree of flexibility in the dynamic specification of the models, and testing the order of integration of the series from a fractional viewpoint allows us to consider the possibility of nonstationary mean reverting processes with shock having transitory though with long lasting effects. Moreover, data from very long time series will be used to benefit from the larger sample size. We have focused on OECD countries for several reasons. With a gross domestic product worth US\$52 trillion (at 2010 prices), OECD nations was responsible for 63\% of world's GDP in 2018 (World Bank, 2020). Secondly, OECD nations have witnessed $\mathrm{SO}_{2}$ emissions growth in majority of the sample period. $\mathrm{SO}_{2}$ emissions increased by almost 200 times between 1750 and 2014 in the OECD countries (Hoesly et al., 2018). Thirdly, OECD nations was responsible for $15 \%$ $\mathrm{SO}_{2}$ emissions in the globe in 2014 (Hoesly et al., 2018). Fourthly, $\mathrm{SO}_{2}$ emission mitigation technologies in OECD nations are usually more efficient than those in existence in non-OECD nations. Several non-OECD nations refer to OECD nations when articulating their $\mathrm{SO}_{2}$ emission mitigation blueprints. 

the following section. The methodology and data are presented in the Section 3 . The fourth section discusses the main findings of the work. Finally, the conclusions of this research are presented in Section 5.

\section{Literature review}

Based on the existing correlation between economic development and environmental pollution, most of the current literature has focused on the Environmental Kuznets Curve (EKC) model as the main framework (Asumadu Sarkodie and Strezov, 2019). Thus, for example, Zhou et al. (2017) examined the relationship between $\mathrm{SO}_{2}$ emissions and economic development by means of a spatial panel model and suggesting an inversely $\mathrm{N}$ shaped environmental Kuznets curve. Other researchers suggested that air pollution is also related to a country's international trade which, in turn, promotes economic growth (Managi et al, 2008). from December 2014 to June 2019. Their results indicate that $\mathrm{SO}_{2}$ emissions per capita in 72 out of 74 cities were convergent. They also conclude that the nonstationary behavior of $\mathrm{SO}_{2}$ emissions per capita in these cities is asymmetrically persistent at different quantiles. 

in to investigate the impact of natural factors on $\mathrm{SO}_{2}$ concentrations. The results indicated that precipitation exerts a significant effect on $\mathrm{SO}_{2}$ reduction and temperature factors seems to aggravate $\mathrm{SO}_{2}$ concentrations.

There are also studies on air pollution persistence. Meraz et al. (2015) used a long range dependence technique based on the rescaled range analysis $(\mathrm{R} / \mathrm{S})$ to examine the level of persistence of air pollutants in Mexico City. The air-pollution time series were hourly observations of nitrogen dioxide, ozone, sulfur dioxide and particulate matter obtained at the Mexico City downtown monitoring station from 1999 to 2014. The results

sulfur dioxide emissions have been rarely discussed. Despite substantial overall 
172 sources (e.g., coal-fired power plants) continues to have significant impacts on the

173 environment ( $\mathrm{Li}$ et al., 2020). Connecting the convergence hypothesis and the degree of 174 persistence of sulfur dioxide $\left(\mathrm{SO}_{2}\right)$ emissions is important for environmental 175 policymakers to effectively implement sulfur emission reduction strategies on a global 176 scale.

3. Data and Methodology

3.1 Data

The $\mathrm{SO}_{2}$ emissions dataset (in kilotonnes or kt) in 37 OECD nations for the period, 17502014, was obtained from the Joint Global Change Research Institute ${ }^{12}$. Australia is the only exception as it has dataset for only 1781-2014. The data was obtained within the Community Emissions Data System (CEDS) and has many advantages over the other sources of $\mathrm{SO}_{2}$ emissions as they usually lack duplicability and uncertainty estimates (Hoesly et al., 2018). CEDS uses emission factors, current emission inventories and activity/driver data to generate annual national emissions across time and there are stages involved in the calculation phase. The first stage encompasses collection of data and the processing of data into a consistent format and timescale. In the second stage, default emissions for several OECD nations for 1960 to 2014 are calculated using driver and emission factor data. The drivers used in the computation include energy consumption (which is used as a driver for fuel combustion emissions), population (used as a driver for non-combustion emissions). In the third step, default estimates are scaled in order to be consistent with present emission inventories where available, plausible and complete. In the fourth step, scaled emission estimates are extended back to 1750 to obtain final

\footnotetext{
${ }^{1}$ The data is available in https://zenodo.org/record/3606753\#.XqLGoMgzbIU.

${ }^{2}$ The list is based on OECD membership as at 30/6/2020. The list was generated from https://www.oecd.org/about/document/list-oecd-member-countries.htm.
} 
national emissions. Finally, emissions are scrutinized and collated to extract data for release and analysis (Hoesly et al., 2018).

Some relevant statistics of the series are presented in Table 1 and it is shown that with an average of 8576.478 kilotonnes of $\mathrm{SO}_{2}$ emissions, the U.S. (which has the largest economy in the globe) was the biggest emitter among the OCED countries during the period under investigation. The U.S. is also among the countries with the largest standard deviation. The Skewness statistic suggests the majority of the series are not skewed. Hence, the logged transformed data is used for the empirical analysis.

Table 1: Descriptive statistics of the series

\begin{tabular}{|c|c|c|c|c|}
\hline Series & Mean & Standard deviation & Minimum value & Maximum value \\
\hline Australia & 427.672 & 554.441 & 0.000 & 1816.861 \\
\hline Austria & 79.022 & 99.663 & 1.884 & 377.456 \\
\hline Belgium & 239.230 & 261.348 & 5.851 & 1028.546 \\
\hline Canada & 1117.430 & 1526.571 & 0.237 & 5422.850 \\
\hline Chile & 428.136 & 657.640 & 0.099 & 2396.017 \\
\hline Colombia & 32.720 & 56.469 & 0.145 & 188.882 \\
\hline Czech Republic & 490.288 & 605.728 & 2.767 & 2152.669 \\
\hline Denmark & 58.707 & 120.327 & 0.911 & 608.662 \\
\hline Estonia & 40.814 & 66.938 & 0.049 & 274.179 \\
\hline Finland & 60.734 & 123.428 & 0.026 & 688.524 \\
\hline France & 598.335 & 718.816 & 32.477 & 3204.397 \\
\hline Germany & 2167.125 & 2577.280 & 11.967 & 8330.618 \\
\hline Greece & 83.455 & 164.850 & 0.312 & 599.538 \\
\hline Hungary & 302.672 & 421.279 & 3.985 & 1494.954 \\
\hline Iceland & 2.225 & 4.275 & 0.003 & 20.012 \\
\hline Ireland & 44.391 & 62.441 & 2.791 & 234.618 \\
\hline Israel & 57.120 & 119.958 & 0.023 & 450.889 \\
\hline Italy & 390.473 & 778.997 & 4.290 & 3386.328 \\
\hline Japan & 531.588 & 883.988 & 2.017 & 4591.322 \\
\hline Korea & 100.970 & 214.413 & 2.385 & 825.518 \\
\hline Latvia & 19.920 & 38.652 & 0.443 & 165.179 \\
\hline Lithuania & 32.767 & 61.593 & 0.981 & 256.506 \\
\hline & & & & \\
\hline & & & & \\
\hline & & & & \\
\hline
\end{tabular}




\begin{tabular}{|c|c|c|c|c|}
\hline Luxembourg & 4.380 & 10.923 & 0.042 & 55.445 \\
\hline Mexico & 380.199 & 650.110 & 0.776 & 2362.333 \\
\hline Netherlands & 90.620 & 155.180 & 2.628 & 732.978 \\
\hline New Zealand & 25.708 & 30.083 & 0.005 & 97.614 \\
\hline Norway & 31.567 & 43.387 & 0.183 & 169.107 \\
\hline Poland & 693.513 & 945.176 & 7.368 & 3628.186 \\
\hline Portugal & 43.241 & 79.520 & 0.639 & 364.384 \\
\hline Slovakia & 95.674 & 143.218 & 0.973 & 622.175 \\
\hline Slovenia & 15.627 & 34.714 & 0.046 & 198.721 \\
\hline Spain & 386.353 & 692.523 & 3.039 & 3020.669 \\
\hline Sweden & 92.522 & 187.930 & 1.433 & 925.952 \\
\hline Switzerland & 27.362 & 41.999 & 0.359 & 201.037 \\
\hline Turkey & 302.826 & 669.287 & 1.145 & 2549.460 \\
\hline United Kingdom & 2425.585 & 2070.001 & 101.381 & 6311.099 \\
\hline United States & 8576.478 & 9573.654 & 2.130 & 29552.055 \\
\hline
\end{tabular}

The series are in their original forms (in kilotonnes or kt)

\subsection{Methodology}

209 Persistence is examined in this paper by using long range dependence techniques based 210 on fractional integration that means that fractional differences are used in the 211 differentiation of the series to render it stationary $\mathrm{I}(0)$.

212 We start by defining $\mathrm{I}(0)$ stationarity. A process $\left\{\mathrm{u}_{\mathrm{t}}, \mathrm{t}=0, \pm 1, \ldots\right\}$ is said to be $213 \mathrm{I}(0)$ or integrated of order 0 if its spectral density function (which is the Fourier 214 transformation of the autocovariances) is finite and strictly positive at all frequencies.

215 Then, a process is said to be $\mathrm{I}(\mathrm{d})$ or integrated of order $\mathrm{d}$ if it can be expressed as:

$$
(1-B)^{d} x_{t}=u_{t}, \quad t=1,2, \ldots,
$$

217 where $\mathrm{B}$ is the backshift operator $\left(\mathrm{Bx}_{\mathrm{t}}=\mathrm{x}_{\mathrm{t}-1}\right)$, the parameter $\mathrm{d}$ can be a fractional value and $\mathrm{u}_{\mathrm{t}}$ is stationary $\mathrm{I}(0)$ like a white noise or a stationary ARMA-type process. 
degree of persistence in the data, noting that equation (1) can be expressed for any real

value d as:

$$
x_{t}=d x_{t-1}-\frac{d(d-1)}{2} x_{t-2}+\ldots+u_{t}
$$

Thus, the higher the value of $d$ is, the higher the level of association will be between the observations. Moreover, this specification is quite general since it allows us to consider different alternative modelling approaches such as short memory or $\mathrm{I}(0)$ processes $(d=$ $0)$, stationarity with long memory $(0<\mathrm{d}<0.5)$; nonstationarity though mean reverting processes $(0.5 \leq d<1)$, unit roots $(d=1)$ and explosive processes $(d>1)$. the Whittle function, which is an approximation to the likelihood function. In more detail, we employ a testing procedure proposed in Robinson (1994) that has various advantages with respect to other approaches. Thus, it can be used for any value of $\mathrm{d}$, including values above 0.5 in the nonstationary range; its limit distribution is a standard $\mathrm{N}(0,1)$ and this behavior holds regardless of whether deterministic terms such as an intercept and a linear time trend are included in the model. ${ }^{3}$

\section{Empirical results}

237 We examine the model given by the following equation,

$$
y_{t}=\alpha+\beta t+x_{t}, \quad(1-B){ }^{d} x_{t}=u_{t}, \quad t=1,2, \ldots
$$

\footnotetext{
${ }^{3}$ The functional form of the version of the tests of Robinson (1994) used in this work can be found in GilAlana and Robinson (1997). The use of other approaches such as Sowell's (1992) maximum likelihood method or the semiparametric method of Geweke and Porter-Hudak (1987) produced almost identical results to those reported in this work.
} 
where $y_{t}$ is the time series we observe, $\alpha$ and $\beta$ are unknown parameters referring respectively to an intercept and a linear time trend, and the regression errors, $\mathrm{x}_{\mathrm{t}}$ are integrated of order $\mathrm{d}$, so that $\mathrm{u}_{\mathrm{t}}$ is an integrated of order 0 process.

In Table 2 we suppose $u_{t}$ is an uncorrelated process, so there is no other time dependence across the data than the one produced by the fractionally differenced parameter $d$. We report in the table the estimates of $d$ in equation (3) under three different modelling specifications for the deterministic terms. Thus, in the second column, we present the results supposing that the two coefficients $\alpha$ and $\beta$ are equal to 0 a priori, so no deterministic components are included in the model; in the third column, we report the estimated values of $d$ under the assumption that $\alpha$ is unknown and $\beta=0$ a priori, i.e., including a constant in the regression model. We have marked in bold the selected specification for each series. This selection is based on the significance of the coefficients in the d-differenced regression. We see that there are only three countries with a significant time trend. They are Colombia, Mexico and Turkey, and in the three of them the time trend is found to be positive (unreported). Focusing on the differencing parameter, we notice evidence of mean reversion only for Chile, Colombia and Mexico, which are the only three Latin American countries in the sample. Here, any shock affecting the series will have a transitory though long lasting effect. On the other hand, there are thirteen countries where the unit root null hypothesis $(\mathrm{d}=1)$ cannot be rejected, while for the remaining 22 the estimated value of $d$ is significantly higher than one, especially for Latvia (1.41), the Netherlands and Japan (1.49).

Table 2: Estimates of the differencing parameter: White noise errors

\begin{tabular}{|c|cc|cc|cc|}
\hline Country & \multicolumn{2}{|c|}{ No terms } & \multicolumn{2}{c|}{ With an intercept } & \multicolumn{2}{c|}{ With a linear trend } \\
\hline AUSTRALIA & $\mathbf{1 . 0 3} \quad(\mathbf{0 . 9 4}, \mathbf{1 . 1 5})$ & 1.03 & $(0.94,1.15)$ & $1.03 \quad(0.94,1.15)$ \\
\hline AUSTRIA & $\mathbf{1 . 0 5} \quad(\mathbf{0 . 9 7}, \mathbf{1 . 1 4})$ & 1.05 & $(0.97,1.14)$ & $1.05 \quad(0.97,1.14)$ \\
\hline
\end{tabular}




\begin{tabular}{|c|c|c|c|}
\hline BELGIUM & $1.18(1.08,1.31)$ & $1.18(1.08,1.31)$ & $1.18(1.08,1.31)$ \\
\hline CANADA & $1.16(1.10,1.25)$ & $1.16(1.10,1.25)$ & $1.16(1.10,1.25)$ \\
\hline SWITZERLAND & $1.16(1.09,1.25)$ & $1.16(1.09,1.25)$ & $1.16(1.09,1.25)$ \\
\hline CHILE & $0.92(0.87,0.98)$ & $0.92(0.87,0.98)$ & $0.92 \quad(0.87,0.98)$ \\
\hline COLOMBIA & $0.83(0.79,0.89)$ & $0.83(0.79,0.89)$ & $0.82(0.78,0.89)$ \\
\hline CZECK & $1.27(1.19,1.37)$ & $1.27(1.19,1.37)$ & $1.27(1.19,1.37)$ \\
\hline GERMANY & $1.14(1.06,1.26)$ & $1.14(1.06,1.26)$ & $1.14(1.06,1.26)$ \\
\hline DENMARK & $1.08(1.01,1.15)$ & $1.08(1.01,1.15)$ & $1.08(1.01,1.15)$ \\
\hline SPAIN & $1.12(1.06,1.20)$ & $1.12(1.06,1.20)$ & $1.12(1.06,1.20)$ \\
\hline ESTONIA & $1.06(0.99,1.16)$ & $1.06(0.99,1.16)$ & $1.06(0.99,1.16)$ \\
\hline FINLAND & $1.18(1.09,1.29)$ & $1.18(1.09,1.29)$ & $1.18(1.09,1.29)$ \\
\hline FRANCE & $1.17(1.10,1.26)$ & $1.17(1.10,1.26)$ & $1.17(1.10,1.26)$ \\
\hline GREAT BRITAIN & $0.99(0.95,1.04)$ & $0.99 \quad(0.95,1.04)$ & $0.99(0.95,1.04)$ \\
\hline GREECE & $1.46(1.37,1.55)$ & $1.46(1.37,1.55)$ & $1.46(1.37,1.55)$ \\
\hline HUNGARY & $1.23(1.16,1.32)$ & $1.23(1.16,1.32)$ & $1.23(1.16,1.32)$ \\
\hline IRELAND & $0.97(0.90,1.07)$ & $0.97 \quad(0.90,1.07)$ & $0.97 \quad(0.90,1.07)$ \\
\hline ICELAND & $1.11(1.03,1.20)$ & $1.11(1.03,1.20)$ & $1.11(1.03,1.20)$ \\
\hline ISRAEL & $1.02(0.96,1.09)$ & $1.02(0.96,1.09)$ & $1.02(0.96,1.09)$ \\
\hline ITALY & $1.35(1.27,1.45)$ & $1.35(1.27,1.45)$ & $1.35 \quad(1.27,1.45)$ \\
\hline JAPAN & $1.49(1.39,1.61)$ & $1.49(1.39,1.61)$ & $1.49(1.39,1.61)$ \\
\hline KOREA & $1.33(1.28,1.40)$ & $1.33(1.28,1.40)$ & $1.33(1.28,1.40)$ \\
\hline LITHUANIA & $1.07(1.02,1.14)$ & $1.07(1.02,1.14)$ & $1.07 \quad(1.02,1.14)$ \\
\hline LUXEMBOURG & $1.35(1.26,1.46)$ & $1.35(1.26,1.46)$ & $1.35(1.26,1.46)$ \\
\hline LATVIA & $1.41(1.35,1.49)$ & $1.41(1.35,1.49)$ & $1.41 \quad(1.35,1.49)$ \\
\hline MEXICO & $0.83(0.79,0.89)$ & $0.83(0.79,0.89)$ & $0.82 \quad(0.79,0.88)$ \\
\hline NETHERLANDS & $1.45(1.32,1.61)$ & $1.45(1.32,1.61)$ & $1.45 \quad(1.32,1.61)$ \\
\hline NORWAY & $1.02(0.95,1.13)$ & $1.02(0.95,1.13)$ & $1.02(0.95,1.13)$ \\
\hline NEW ZEALAND & $1.00(0.93,1.10)$ & $1.00(0.93,1.10)$ & $1.00 \quad(0.93,1.10)$ \\
\hline POLAND & $1.00(0.94,1.09)$ & $1.00(0.94,1.09)$ & $1.00 \quad(0.94,1.09)$ \\
\hline PORTUGAL & $1.00(0.94,1.08)$ & $1.00(0.94,1.08)$ & $1.00(0.94,1.08)$ \\
\hline SLOVAKIA & $1.25(1.19,1.32)$ & $1.25(1.19,1.32)$ & $1.25(1.19,1.32)$ \\
\hline SLOVENIA & $1.01(0.93,1.11)$ & $1.01 \quad(0.93,1.11)$ & $1.01 \quad(0.93,1.11)$ \\
\hline SWEDEN & $1.24(1.17,1.32)$ & $1.24(1.17,1.32)$ & $1.24(1.17,1.32)$ \\
\hline TURKEY & $1.06(1.00,1.14)$ & $1.06(1.00,1.14)$ & $1.06(1.00,1.14)$ \\
\hline UNITED STATES & $1.00(0.94,1.08)$ & $1.00(0.94,1.08)$ & $1.00(0.94,1.08)$ \\
\hline
\end{tabular}



be rejected at the 5\% level. In bold, the selected model for each series in relation with the deterministic terms.

267 autocorrelated. Here, we use the exponential spectral model of Blomfield (1973) which

268 approximates autoregressive components in a very simple way. The time trend is now

269 only required in the case of Australia. The estimated values of $d$ are now much higher

270 than in the previous case of white noise disturbances, and there is no evidence of mean

271 reversion in any single case. The hypothesis of unit root (i.e., I(1) behavior) cannot be

272 rejected in 15 countries, and in 22 the estimated value of $\mathrm{d}$ is found to be significantly

273 higher than one.

274 
Table 3: Estimates of the differencing parameter: Autocorrelated errors

\begin{tabular}{|c|c|c|c|}
\hline Country & No terms & With an intercept & With a linear trend \\
\hline AUSTRALIA & $0.95 \quad(0.85,1.12)$ & $0.95 \quad(0.85,1.12)$ & $0.94(0.83,1.12)$ \\
\hline AUSTRIA & $1.13(0.95,1.34)$ & $1.13(0.95,1.34)$ & $1.13(0.95,1.34)$ \\
\hline BELGIUM & $0.97(0.86,1.13)$ & $0.97 \quad(0.86,1.13)$ & $0.97 \quad(0.86,1.13)$ \\
\hline CANADA & $1.13(1.03,1.25)$ & $1.13(1.03,1.25)$ & $1.13(1.03,1.25)$ \\
\hline SWITZERLAND & $1.23(1.09,1.39)$ & $1.23(1.09,1.39)$ & $1.23(1.09,1.39)$ \\
\hline CHILE & $1.32(1.17,1.49)$ & $1.32(1.17,1.49)$ & $1.32(1.17,1.49)$ \\
\hline COLOMBIA & $1.08(0.97,1.23)$ & $1.08(0.97,1.23)$ & $1.07(0.97,1.23)$ \\
\hline CZECK & $1.21(1.09,1.36)$ & $1.21(1.09,1.36)$ & $1.21 \quad(1.09,1.36)$ \\
\hline GERMANY & $1.05(0.92,1.22)$ & $1.05(0.92,1.22)$ & $1.05(0.92,1.22)$ \\
\hline DENMARK & $1.26(1.14,1.40)$ & $1.26(1.14,1.41)$ & $1.26(1.14,1.41)$ \\
\hline SPAIN & $1.28(1.16,1.44)$ & $1.28(1.16,1.44)$ & $1.28(1.16,1.44)$ \\
\hline ESTONIA & $0.96(0.86,1.08)$ & $0.96 \quad(0.86,1.08)$ & $0.96 \quad(0.86,1.08)$ \\
\hline FINLAND & $1.02(0.88,1.21)$ & $1.02(0.88,1.21)$ & $1.02(0.88,1.21)$ \\
\hline FRANCE & $1.39(1.22,1.61)$ & $1.40 \quad(1.22,1.61)$ & $1.40 \quad(1.22,1.61)$ \\
\hline GREAT BRITAIN & $1.35(1.24,1.51)$ & $1.35(1.24,1.51)$ & $1.35(1.24,1.51)$ \\
\hline GREECE & $1.50(1.36,1.72)$ & $1.50(1.36,1.72)$ & $1.50(1.36,1.72)$ \\
\hline HUNGARY & $1.25(1.14,1.39)$ & $1.25(1.14,1.39)$ & $1.25(1.14,1.39)$ \\
\hline IRELAND & $0.96(0.85,1.11)$ & $0.97 \quad(0.85,1.11)$ & $0.97 \quad(0.85,1.11)$ \\
\hline ICELAND & $1.08(0.96,1.24)$ & $1.08(0.96,1.24)$ & $1.09(0.96,1.25)$ \\
\hline ISRAEL & $1.31(1.18,1.54)$ & $1.31(1.18,1.54)$ & $1.32(1.18,1.54)$ \\
\hline ITALY & $1.35(1.24,1.51)$ & $1.35(1.24,1.51)$ & $1.35(1.24,1.51)$ \\
\hline JAPAN & $1.29(1.07,1.57)$ & $1.29(1.07,1.57)$ & $1.29(1.07,1.57)$ \\
\hline KOREA & $1.73(1.58,1.90)$ & $1.72(1.58,1.90)$ & $1.72(1.58,1.90)$ \\
\hline LITHUANIA & $1.35(1.22,1.50)$ & $1.35 \quad(1.22,1.50)$ & $1.35 \quad(1.22,1.50)$ \\
\hline LUXEMBOURG & $1.29(1.10,1.52)$ & $1.29(1.10,1.52)$ & $1.29(1.10,1.52)$ \\
\hline LATVIA & $1.63(1.49,1.83)$ & $1.63(1.49,1.83)$ & $1.63(1.49,1.83)$ \\
\hline MEXICO & $1.01(0.93,1.11)$ & $1.01 \quad(0.93,1.11)$ & $1.01 \quad(0.92,1.11)$ \\
\hline NETHERLANDS & $1.05(0.90,1.28)$ & $1.05(0.90,1.28)$ & $1.05(0.90,1.28)$ \\
\hline NORWAY & $0.94(0.83,1.08)$ & $0.94 \quad(0.83,1.08)$ & $0.94 \quad(0.83,1.08)$ \\
\hline NEW ZEELAND & $1.06(0.92,1.26)$ & $1.06(0.92,1.26)$ & $1.06 \quad(0.92,1.26)$ \\
\hline POLAND & $1.14(1.01,1.30)$ & $1.14(1.01,1.30)$ & $1.14(1.01,1.30)$ \\
\hline PORTUGAL & $1.25(1.10,1.41)$ & $1.25(1.10,1.41)$ & $1.25(1.10,1.41)$ \\
\hline SLOVAKIA & $1.42(1.30,1.56)$ & $1.42(1.30,1.56)$ & $1.42(1.30,1.56)$ \\
\hline
\end{tabular}




\begin{tabular}{|c|ll|lll|ll|}
\hline SLOVENIA & $\mathbf{1 . 0 6}$ & $\mathbf{( 0 . 8 9 ,}$ & $\mathbf{1 . 2 9})$ & 1.06 & $(0.89,1.29)$ & 1.06 & $(0.89,1.29)$ \\
\hline SWEDEN & $\mathbf{1 . 3 3}$ & $\mathbf{( 1 . 2 0 ,}$ & $\mathbf{1 . 4 9})$ & 1.33 & $(1.20,1.49)$ & 1.33 & $(1.20,1.49)$ \\
\hline TURKEY & $\mathbf{1 . 0 9}$ & $\mathbf{( 1 . 0 1}, \mathbf{1 . 2 1})$ & 1.09 & $(1.01,1.21)$ & 1.10 & $(1.01,1.20)$ \\
\hline UNITED STATES & $\mathbf{1 . 0 4}$ & $\mathbf{( 0 . 9 4}, \mathbf{1 . 1 7})$ & 1.04 & $(0.94,1.17)$ & 1.04 & $(0.94,1.17)$ \\
\hline
\end{tabular}

The values in parenthesis are the confidence intervals of the values of $d$ where the null hypothesis cannot be rejected at the 5\% level. In bold, the selected model for each series in relation with the deterministic terms.

\section{Concluding comments}

In this paper we have examined the stochastic properties of the $\mathrm{SO}_{2}$ emissions in 37

OECD countries by looking at their degree of differentiation from a fractional viewpoint.

This methodology is more general than the classical one that is based exclusively on integer values for the order of integration. The results indicate that if the error term is uncorrelated, mean reversion occurs in the three Latin American countries, namely Chile, Colombia and Mexico, with orders of integration higher than 0.5 but strictly smaller than one and thus implying long lasting effects of shocks. For all the other countries in the sample, the order of integration is found to be equal to or higher than one implying permanency of shocks. If autocorrelation is permitted, the confidence intervals for the values of the differencing parameter are wider and mean reversion is not found in any single case.

The results presented in this work are of interest for the authorities since lack of mean reversion implies that shocks have a permanent nature; thus, if a negative shock occurs in relation to the $\mathrm{SO} 2$ emissions, strong policies should be adopted by the authorities if it is beneficial to recover the original levels, although the duration of SO2 emissions in the atmosphere might be not as long as what several other pollutants exhibit. In other words, efforts to reduce $\mathrm{SO} 2$ emissions are required when there is an increase in the pollutant as a result of various economic activities such as movements of automobiles 
and heavy equipment that burn fuel with a high sulfur content. On the other hand, the good news is that positive shocks reducing the level of emissions will also be permanent, and no strong actions should then be required.

Another implication of the foregoing results is that there is a need for adequate on investments on mitigation efforts at reducing $\mathrm{SO} 2$ emissions, such as wet systems which involve the use of sorbent materials to reduce $\mathrm{SO} 2$ emissions, especially when a rise in the pollutant is being experienced. This is because the lack of mean reversions in the results implies that the increase in the pollutant will be permanent if adequate investments for mitigation are not available.

The paper can be extended in several directions. More countries should be examined. In particular, the fact that the only three Latin American countries investigated in the paper display some degree of mean reversion is interesting and this might be a specific feature corresponding to this continent. Other potential extensions include the possibility of structural breaks and non-linear issues. Liddle and Messinis (2015) showed substantial breaks and nonlinearities in OECD sulfur emissions so this possibility should also be investigated in the context of fractional integration. In fact, authors such as Diebold and Inoue (2001) and Granger and Hyung (2004) demonstrated that these two issues (nonlinearities and fractional integration) were intimately related. Thus, a natural extension of this work might be to examine the potential presence of breaks in the data, using for instance the approach developed in Gil-Alana (2008) that extends Bai and Perron's (2003) method to the fractional case. In addition, nonlinear deterministic terms can also be included in the model avoiding the abrupt changes produced by the classical structural breaks. Here, we can employ the Chebyshev polynomials in time proposed in Cuestas and Gil-Alana (2016), the Fourier functions (Gil-Alana and Yaya, 2021) or even 
neural networks (Yaya et al., 2021) still in the context of the fractional models used in

325 this work. This line of research is now in progress.

326 
Asumadu Sarkodie, S., Strezov, V. (2019). A review on Environmental Kuznets Curve hypothesis using bibliometric and meta-analysis. Science of The Total Environment. 649. 128-145.

Belbute, J.M. and Pereira, A.M. (2017). Do global CO2 emissions from fossil-fuel consumption exhibit long memory? a fractional-integration analysis. Applied Economics, 49(40): pp.4055-4070.

Bloomfield, P., 1973, An exponential model in the spectrum of a scalar time series, Biometrika 60, 217-226.

Chelani, A.B. (2013). Study of Extreme CO, $\mathrm{NO}_{2}$ and $\mathrm{O}_{3}$ Concentrations at a Traffic Site in Delhi: Statistical Persistence Analysis and Source Identification. Aerosol and Air Quality Research. 13, pp. 377-384.

Chen, Z., Barros, C., \& Gil-Alana, L. (2016). The persistence of air pollution in four mega-cities of China. Habitat International. 56. 103-108.

Cuestas, J.C. and L.A. Gil-Alana (2016). A nonlinear approach with long range dependence based on Chebyshev polynomials, Studies in Nonlinear Dynamics and Econometrics 20, 57-94.

Diebold, F. X., and A. Inoue. (2001). Long Memory and Regime Switching, Journal of Econometrics, 105:1, pp. 131-59.

Environmental Protection Agency (2019). Sulfur Dioxide (SO2) Pollution. Available at https://www.epa.gov/so2-pollution/sulfur-dioxide-basics (accessed on 12/5/21)

Geweke, J. and S. Porter-Hudak (1983), The estimation and application of long memory models, Journal of Time Series Analysis 4, 221-238.

Gil-Alana, L.A. and P.M. Robinson (1997), Testing of unit roots and other nonstationary hypotheses in macroeconomic time series. Journal of Econometrics 80, 241-268.

Gil-Alana, L.A. and Solarin, S.A. (2018). Have US environmental policies been effective in the reduction of US emissions? A new approach using fractional integration. Atmospheric Pollution Research, 9(1): pp.53-60.

Gil-Alana, L.A. and O. Yaya (2021), Testing fractional unit roots with non-linear smooth break approximations using Fourier functions, Journal of Applied Statistics, forthcoming.

Gil-Alana, L., Yaya, O., Awolaja, O. \& Cristofaro, L. (2020). Long Memory and Time Trends in Particulate Matter Pollution (PM2.5 and PM10) in the US States. Journal of Applied Meteorology and Climatology. 59, pp. 1351-1367

Granger, C. W. J., and Hyung, N. (2004). Occasional structural breaks and long memory 
with an application to the S\&P 500 absolute stock returns. Journal of Empirical Finance $11,399-421$.

Hendry, D.F. and Juselius, K. (2000). Explaining cointegration analysis: Part 1. The Energy Journal, 21(1): pp. 1-42.

Hoesly, R. M., Smith, S. J., Feng, L., Klimont, Z., Janssens-Maenhout, G., Pitkanen, T., ... \& Bond, T. C. (2018). Historical (1750-2014) anthropogenic emissions of reactive gases and aerosols from the Community Emissions Data System (CEDS). Geoscientific Model Development (Online), 11(PNNL-SA-123932).

Liddle, B. and G. Messinis, (2015). Revisiting sulfur Kuznets curves with endogenous breaks modeling: Substantial evidence of inverted-Us/Vs for individual OECD countries. Economic Modelling, Vol. 49, pp. 278-285.

Liu, Q., Long, Y., Wang, C., Wang, Z., Wang, Q. and Guan, D. (2019). Drivers of provincial SO2 emissions in China-Based on multi-regional input-output analysis. Journal of Cleaner Production, 238, p.117893.

Managi, S., Hibiki, A., Tsurumi, T. (2008). Does Trade Liberalization Reduce Pollution Emissions? Research Institute of Economy, Trade and Industry (RIETI), Discussion Paper Series 08-E-013.

Meraz, M., Rodriguez, E., Femat, R., Echeverria, J.C. \& Alvarez-Ramirez, J. (2015). Statistical persistence of air pollutants $\left(\mathrm{O}_{3}, \mathrm{SO}_{2}, \mathrm{NO}_{2}\right.$ and $\left.\mathrm{PM}_{10}\right)$ in Mexico City. Physica A: Statistical Mechanics and its Applications. 427: pp. 202-17

Mclinden, C., Fioletov, V., Shephard, M., Krotkov, N., Li, C., Martin, R., \& Moran, M., Joanna, J., (2016). Space-based detection of missing sulfur dioxide sources of global air pollution. Nature Geoscience. 9, pp. 496-500

Nazlioglu, S., \& Karul, C. (2017). A panel stationarity test with gradual structural shifts: re-investigate the international commodity price shocks. Economic Modelling, 61, pp. 181-192.

Newbold, P. and Granger, C.W. (1974). Experience with forecasting univariate time series and the combination of forecasts. Journal of the Royal Statistical Society: Series A (General), 137(2), pp.131-146.

Nieswiadomy, M.L. and Strazicich, M.C. (2004) Are political freedoms converging?. Economic Inquiry, 42(2): pp.323-340.

Robinson, P.M. (1994) Efficient tests of nonstationary hypotheses. Journal of the American Statistical Association. 89, pp.1420-1437.

Sidneva, N. and Zivot, E. (2014). Evaluating the impact of environmental policy on the trend behavior of US emissions of nitrogen oxides and volatile organic compounds. Natural Resource Modeling, 27(3): pp.311-337. 
Solarin, S., Tiwari, A. (2020). Convergence in Sulphur Dioxide (SO2) Emissions Since 1850 in OECD Countries: Evidence from a New Panel Unit Root Test. Environmental Modeling \& Assessment 25, pp. 665-675

Sowell, F., (1992), Maximum likelihood estimation of stationary univariate fractionally integrated time series models, Journal of Econometrics 53, 165-188.

Srivastava, R. K. (2000) Controlling S02 Emissions - A Review of Technologies. Prepared for the U.S. Environmental Protection Agency, EPA/600/R-00/093.

Timilsina, G.R., Dulal, H.B. (2009) A review of regulatory instruments to control environmental externalities from the transport sector. Policy research working paper. The World Bank, Development Research Group, Environment and Energy team.

World Bank (2020). World Development Indicators. Available at www.data.worldbank.org (accessed on 01/04/2020)

Yang, X., Zhang, W., Zhan, D., \& Li, J. (2017). The impact of anthropogenic emissions and meteorological conditions on the spatial variation of ambient SO2 concentrations: A panel study of 113 Chinese cities. Science of The Total Environment. 584, pp. 318-328

Yaya, O., Ogbonna, A.E., Gil-Alana, L.A. and Furuoka, F. (2021). A new unit root analysis for testing hysteresis in unemployment, Oxford Bulletin of Economics and Statistics, forthcoming.

Zhang, Y., Si, D. \& Zhao, Bing. (2020). The Convergence of Sulphur Dioxide (SO2) Emissions Per Capita in China. Sustainability, 12, 1781

Zhou, Z., Ye, X., Ge, X. (2017). The Impacts of Technical Progress on Sulfur Dioxide Kuznets Curve in China: A Spatial Panel Data Approach. Sustainability. Vol 9, nº 4, Art, $n^{\circ} 674$. 